\title{
Effects of media-assisted therapeutic approaches on physical activity of obese adults: a systematic review
}

\author{
Alexandra Ziegeldorf ${ }^{*}$, Petra Wagner and Hagen Wulff
}

\begin{abstract}
Background: The number of patients with obesity continues to increase in our society. At the same time, digitalization defines our everyday life. Therefore, the question arises whether to use digital media for effective treatments against obesity. Aim of this review is a concise presentation of effects of media-assisted therapeutic approaches.
\end{abstract}

Methods: A systematic literature research in multiple scientific databases, PubMed, Web of Science and Cochrane Library, was performed for literature published in the last 10 years (cut-off date 12.07.2017). Only randomized controlled trials using digital support for treatment and/or aftercare of obese adults aged between 18 to 70 years were included into the analysis.

Results: Overall, 14 trials with data on a total of 4979 participants were included in this review. Generally, there are positive trends for increased moderate to vigorous physical activity by the use of digital media. A simultaneous usage of various digital media, which focus on important aspects of activity behavior, has proven to be effective. A combination of various digital media shows the greatest positive effect and could significantly increase physical activity. However, the biggest potential was found in mixed approaches combining digital devices and personal face-to-face support.

Conclusions: Therapeutic approaches using digital media for supporting obesity treatment did not show superior benefit over traditional personal therapeutic methods. Nevertheless, using both methods together offered the greatest potential for successful obesity therapy. However, there is a backlog of transparency concerning information about the content of treatment. Furthermore, there is a lack of valid data about aftercare and followup.

Keywords: Obesity, Therapy, Aftercare, Digital media, Physical activity, Moderate to vigorous physical activity, Adults

\section{Background}

The prevalence of overweight and obesity has trebled since 1975 [1], and poses an enormous risk of accompanying and secondary diseases to patients [2]. As a consequence, healthcare systems face substantial direct and indirect costs [3].

Main risk factors for overweight and obesity are low physical activity and high inactivity, i.e. physical activity with decent intensity under the recommended $150 \mathrm{~min} /$ week $[4,5]$.

There are many different therapeutic approaches used all over the world to reduce patients' individual burdens

\footnotetext{
* Correspondence: alexandra.ziegeldorf@uni-leipzig.de Institute for Exercise and Public Health, Faculty of Sports Science, Leipzig University, Jahnallee 59, 04155 Leipzig, Germany
}

and costs for health care systems [6, 7]. According to international guidelines of obesity treatment, all stationary and ambulatory therapeutic approaches aim to increase physical activity [8].

The use of digital media in therapy has been controversially discussed in the corresponding literature $[9$, 10]. On the one hand, many studies indicate that an increased use of digital media is associated with reduced physical activity and increased risk of overweight and obesity [11-13].

In connection with television-presupposed inactivity some meta-analyses report an increased overall mortality [14], cardiovascular mortality [15] and tumor presupposed

(C) The Author(s). 2020 Open Access This article is distributed under the terms of the Creative Commons Attribution 4.0 International License (http://creativecommons.org/licenses/by/4.0/), which permits unrestricted use, distribution, and 
mortality [16]. Similarly, meta-analyses report an increased morbidity due to metabolic syndrome [11, 17]. On the other hand, digitization offers great potential for therapeutic settings as they may benefit from the use of digital media [18]. Digital media guarantee patients a contemporary, daily access to therapy and may help to facilitate and support therapeutic home care as their use is not bound to any treatment facilities [19]. For therapeutic approaches focused on an obesity-related lifestyle modification, digital media are also used for adoption, maintenance and longterm implementation of a healthy behavior including regular physical activity [20].

Therapeutic approaches use different media. In the study by Cussler et al. [21] emails, chatrooms and platforms were used to support participants in increasing their physical activity (intensity). Furthermore, interactive TV shows [22], text messages [23] and telephone coachings (see also $[24,25]$ ) were used for lifestyle modifications and, in this context, to increase physical activity (intensity). Another approach focused on the difficult access to on-site therapy, which particularly challenging in rural areas. Donelly et al. [26] used conference calls to provide intervention programs to patients who would otherwise not have been able to participate at all.

Overall, empirical findings of therapeutic effects tend to be heterogeneous in terms of the desired increase in physical activity.

In the context of ambulatory and stationary therapy optimization, it is key to determine the efficiency of media-assisted obesity treatment in enhancing physical activity in adults. Therefore, this systematic review aims at analyzing the efficiency of therapeutic approaches using media for obesity treatment in adults.

\section{Methods}

A systematic literature review in multiple databases (PubMed, Web of Science and Cochrane Library) was performed for articles published from January 1st, 2007 to July 12th, 2017. The methodological approach of the review is based on the guidelines of the German Cochrane Community (2013) [27]. The procedure used in this study follows the PRISMA statement [28]. After identifying adequate keywords using the PICO scheme a corresponding search strategy was developed. After the first search and analysis of the results the strategy was modified. Following the final search, all relevant studies were examined and documented; duplicates were removed (Fig. 1). Inclusion criteria included all randomized controlled trials using digital media to support obesity therapy and/or aftercare. Included digital media were internet, PC, TV, video (games), DVD, mobile phone, smartphone, landline telephone and apps. All inclusion and exclusion criteria are listed below.

\section{Inclusion criteria}

- age 18-70

- randomized controlled trials (RCT)

- direct intervention with digital media

- body mass index (BMI) at least $25 \mathrm{~kg} / \mathrm{m}^{2}$ (beginning of intervention)

\section{Exclusion criteria}

- older than 70 / younger than 18 years

- meta-analysis

- intervention objective: reduction of electronic digital media consumption

- no direct intervention but through associated persons (social surroundings)

Control groups were accepted if they got the same intervention without support of digital media or a slimmed-down version, got the same intervention after the intervention group was finished (waiting list) or got no support at all. In case of a waiting list control group, cut-off criteria for inclusion was a maximum waiting time of 1 year.

Outcome variable was physical activity. Measured parameters of physical activity behavior include duration (MVPA min/day), intensity (e.g. METs/week or kcal/day), frequency (number of training units per day or week) and volume (e.g. steps/day or week or total PA) [29].

Search terms were "obesity", "therapy", "aftercare", "intervention", "digital media" and "physical activity" which were differentiated, specified and composed using the Boolsche operators. Therefore, 22,567 studies were identified in the first search. In a second, extended search, exclusion criteria were incorporated in the search strategy. Therefore 311 studies from PubMed, 418 studies from Web of Science and 467 studies from Cochrane Library were identified. Following the identification process, title and abstract of these studies were analyzed and duplicates removed. As a result, the total amount of studies was reduced to 109 . In a last step, the remaining studies were analyzed in full-text, taking into account all inclusion and exclusion criteria. The identification process is shown in Fig. 1.

Approval by an ethic committee was not necessary because only published data were used.

For assessing risk of bias of the studies, the guidelines from Cochrane Germany [30] were used.

\section{Results}

In total, 14 randomized controlled trials (evidence level 1a) could be included in this analysis (Table 1).

Most studies were conducted in the United States of America (8). The remaining studies were from Australia (1), the Netherlands (1), Korea (1), Germany (1), Finland 
(1) and the United Kingdom (1). Most studies included both sexes (11), only two studies included just male participants and one exclusively included black women. The study periods varied from three to maximum 18 months. Most studies covered a time period of 6 months (7), followed by studies with a time period of 3 months (4). Follow-up data were collected in almost half of the studies (6). Sample size ranged from 39 to 1386 participants, with most studies in a three-digit range (10) and two studies with more than a thousand participants. Altogether, data from 4979 participants were analyzed for this review, 3043 of whom received an intervention assisted by digital media. More than half of the studies (8) randomized participants classically bilaterally into one intervention group and one control group. Six studies examined three groups with two intervention groups and one control group (see Table 1).

The digital media used for therapy in the trials werecategorized by author into four groups: cell phone/smartphone (calls, text messages and apps), computer (websites, platforms, emails and social networks), digital bracelet/ pedometer and TV (programs and DVDs). Half of the studies (7) used only one digital device for intervention. Four trials used a combination of two different digital devices. The remaining three trials used more than two digital devices and were categorized as "multimedia" (Table 2).

Most studies provided therapy, two of them only provided aftercare [21,37] and only one study provided both [22] (see Table 1). Therapies were usually constructed modularly and addressed topics like dietary behavior, physical activity, behavior change strategies and overcoming barriers. Therefore, most online interventions created websites with personalized access for study participants, which allowed them to work independently on specific topics and to participate in discussion forums. In most cases expert advisors gave patients individual feedback by email or supported them by telephone regarding topics they worked on, answered questions, gave additional advice and provided information about the topics if needed or requested. Furthermore, coaching sessions on the phone focused on behavior changes, discussions on barriers, successes and failures and advice

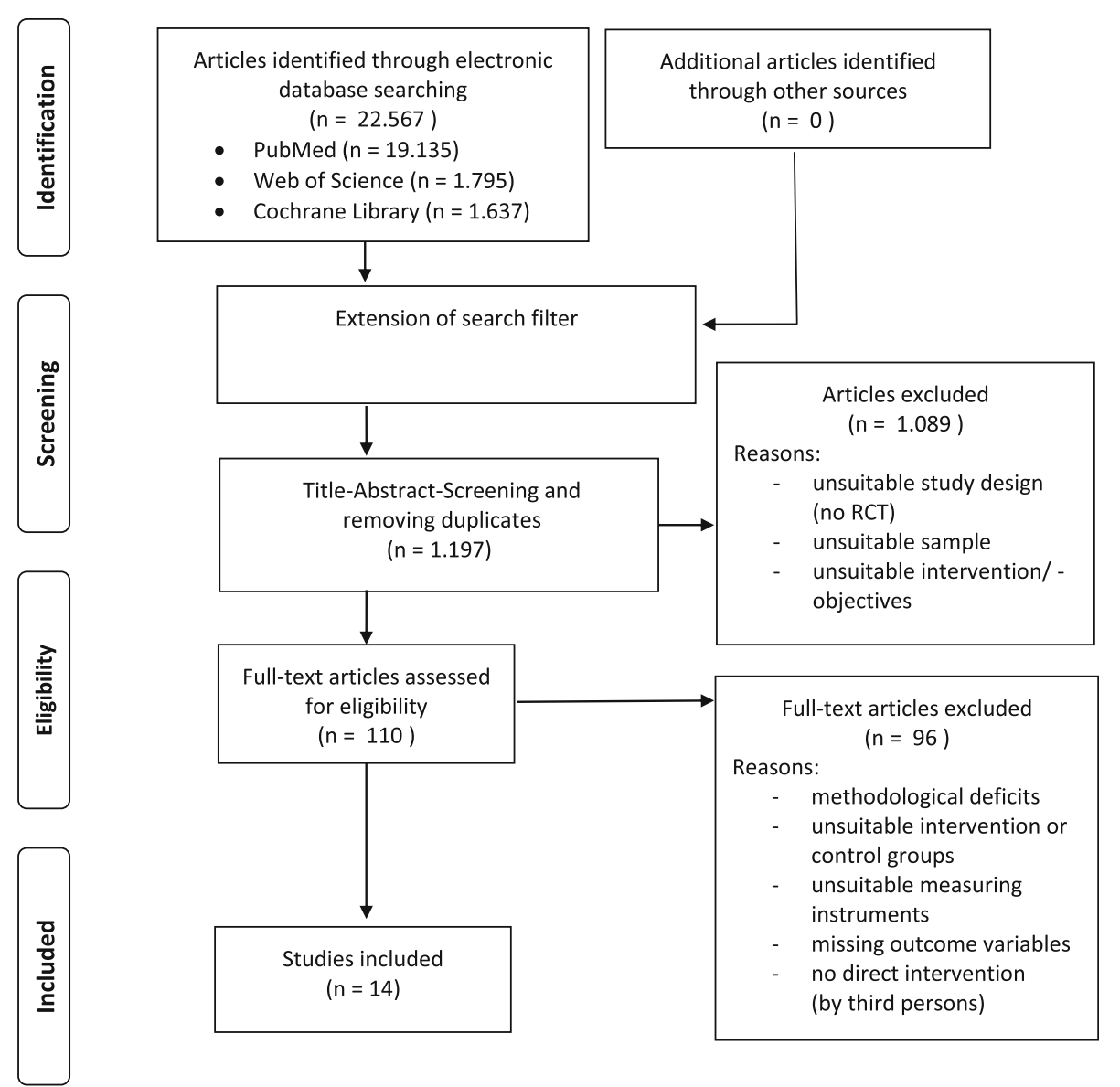

Fig. 1 Flow chart diagram (PRISMA 2009) [28] describing selection of studies for the systematic review of Effects of media-assisted therapeutic approaches on physical activity of obese adults (identified, screened, eligible and included studies). Articles may have been excluded for more than one reason 


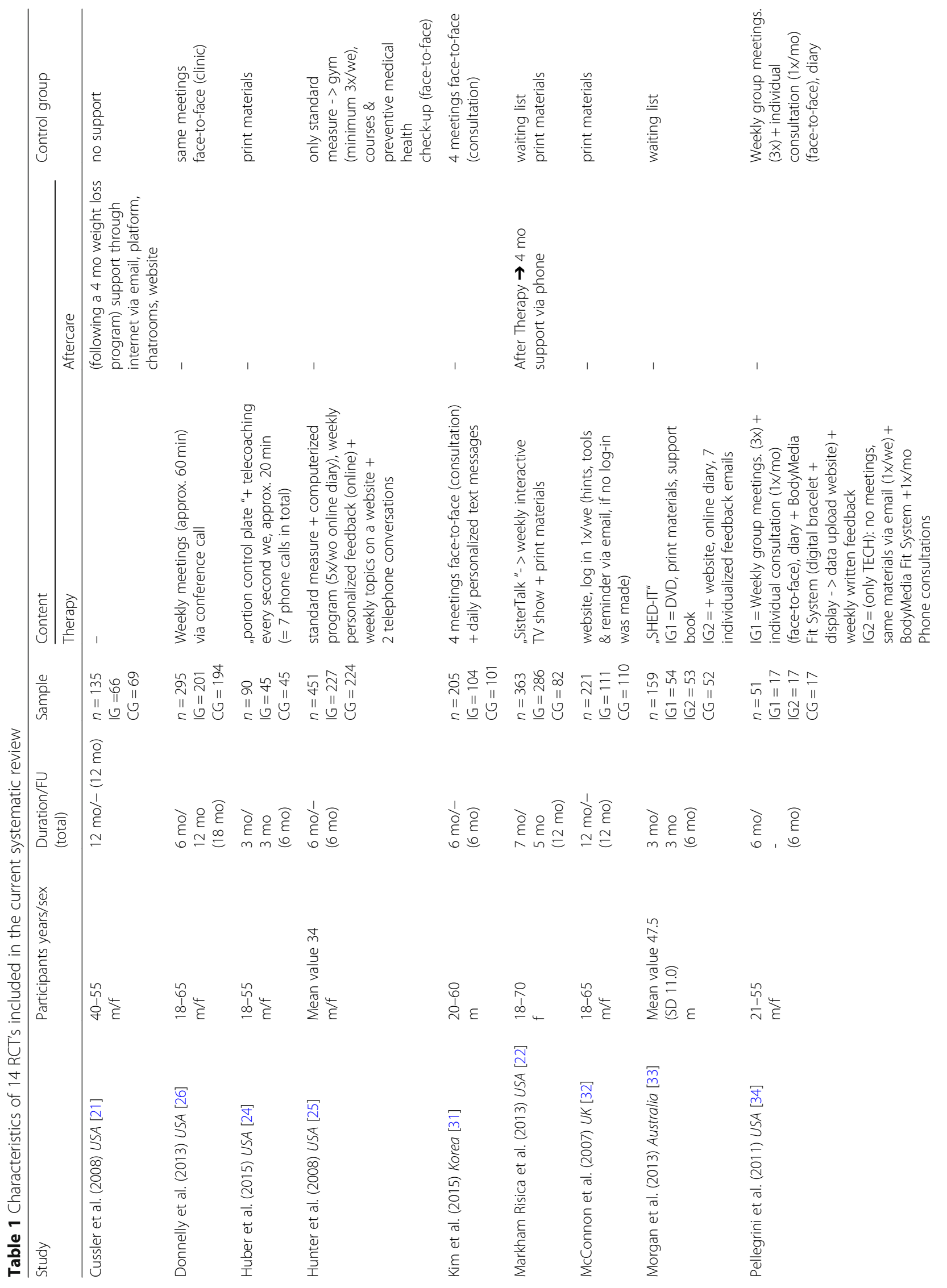




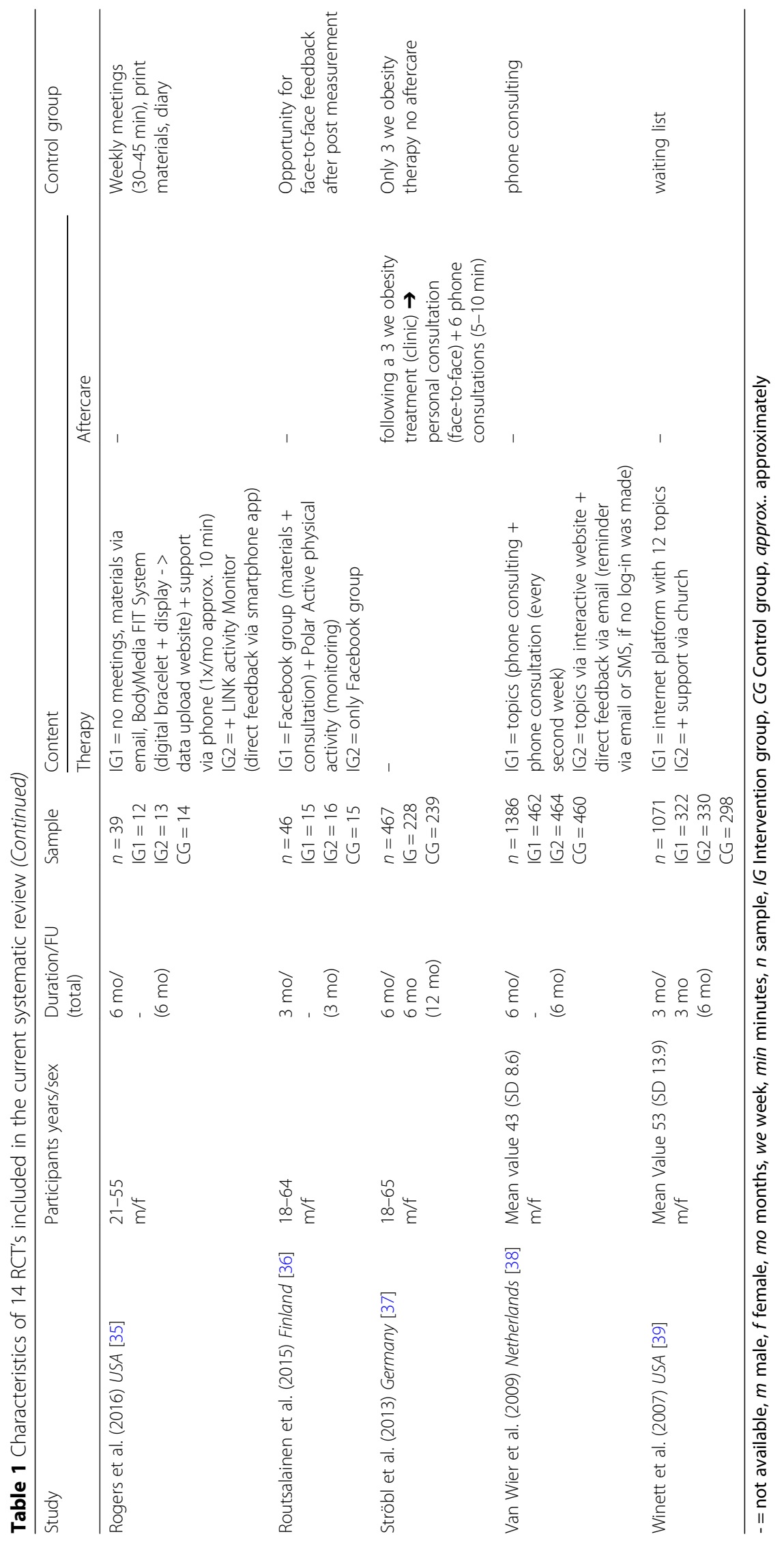


Table 2 Digital devices used for obesity treatment in the 14 RCT's included in the current systematic review

\begin{tabular}{ll}
\hline Digital devices & Amount \\
\hline Phone/ smartphone & 4 \\
Computer & 3 \\
Phone/ smartphone \& computer & 1 \\
Computer \& pedometer/ digital bracelet & 1 \\
Computer \& TV & 1 \\
Phone/ smartphone \& TV & 1 \\
Multimedia & 3 \\
$\Sigma=$ & 14 \\
\hline
\end{tabular}

about patients' action plans for the upcoming period [24]. Emails and text messages were used as automated reminders to "chase" participants who did not log in or upload their data within the agreed timeframe $[32,38]$. Moreover, few studies used emails, text messages and phone calls to motivate participants (see Table 1).

One trial allowed participants to attend regular therapy sessions via conference call [26].

In the trials which used digital bracelets in therapy, participants received direct feedback about their activity from the display. Also after upload of the data by participants, expert advisors assessed the data with special software and gave participants individual feedback and additional guidance based on the analysis of their personal data [34-36].

One study used a public social network (Facebook) as communication platform [36]. Two studies integrated TV in their therapy to deliver content, one used an interactive TV show [22] and another one used a DVD to support their therapy [33].

In addition, two studies performed only media-assisted aftercare. One provided online support via email, platform, chatroom and a website [21] and the other provided face-to-face consultations via video calls [37].

The control groups mostly received the same material and information about diet, physical activity and positive behavioral change like the intervention group, but only in printed form and/or got face-to-face meetings or personal conversation with the therapist. Three trials applied the so-called "waiting list" method to their control group and two trials did not support their control group at all (see Table 1).

The analyzed studies used different kinds of instruments for measuring the physical activity outcome. Four studies used accelerometer-based measuring tools (BodyMedia FIT System (Jawbone); Polar Electro Kempele Oy; ActiGraph GT1X; ActiGraph GT3X; Actigraph LLC) and pedometer-based measuring tools (Yamax SW-200; WA101, Accusplit AE120). The majority of studies (10) used self-reporting measuring methods. Three of them used the International Physical Activity Questionnaire (IPAQ) [40], one of them the short form (IPAQ-SF) [41]. The remaining trials used the Seven-Day Physical Activity Recall Interview [42], the Paffenbarger Physical Activity Questionnaire [43], the Self-Reported Physical Activity and Screen Time Questionnaire [44], the Freiburg Questionnaire for Physical Activity [45], the Short Questionnaire to Asses Health-Enhancing Physical Activity (SQUASH) [46], the Beacke Physical Activity Questionnaire [47], and the Godin Leisure-Time Exercise Questionnaire [48]. One study did not specify the therein used self-reporting instruments [26]. Two studies used a combination of accelerometer based and self-reporting instruments $[26,36]$ (Table 3).

Studies also differed in terms of parameters that were used for objectifying physical activity (Table 3). Eleven trials found an increase in physical activity during the intervention period from baseline to the most recent measurement (time effect), four of them were significant. Furthermore, two studies found no differences during time and two studies reported a decrease in physical activity from baseline to final measurement. Control groups revealed similar results. Ten out of fourteen studies show an increase in physical activity between baseline and final measurement, three of them were significant. Four studies reported a decrease in physical activity in their control groups and one study did not find any time effect, neither for the intervention group nor for the control group. Reported results regarding the time"group effect are relatively homogeneous. Four out of fourteen studies were able to prove a positive effect, two of them only partial. Only one study showed a significant time"group effect in increasing physical activity [33]. The twelve remaining studies report no significant time*group effect when comparing the intervention and the control group during the intervention period (Table 3). Only two studies recorded their effect size. Morgan et al. [33] report a moderate effect (Cohen's $d$ ) and Ströbl et al. [37] report a small effect $\left(\eta^{2}\right)$ [49].

In addition, most of the studies were also collecting and analyzing anthropometric data to calculate the Body Mass Index (BMI) as well as lifestyle-relevant behaviors like dietary behavior.

\section{Limitations}

In the course of the implemented risk of bias assessment in this systematic review, none of the identified studies need to be excluded due to excessive risk of bias.

Regarding the results of this systematic review, the authorship would like to point out a few limitations. Some studies do not report information about significances of the results regarding the time effects within their study groups. Time*group effects were reported in all studies, mostly stating $p$-values. Also some studies 
Table 3 Characterization of measuring instruments, parameters and outcomes in the 14 included RCT's

\begin{tabular}{|c|c|c|c|c|c|c|}
\hline \multirow[t]{2}{*}{ Study } & \multirow[t]{2}{*}{ Measuring instrument(s) } & \multirow[t]{2}{*}{ Parameter } & \multicolumn{3}{|c|}{ time-effect (PA) } & \multirow{2}{*}{$\begin{array}{l}\text { time }^{*} \text { group- } \\
\text { effect (PA) }\end{array}$} \\
\hline & & & IG 1 & IG 2 & $\mathrm{CG}$ & \\
\hline Cussler et al. (2008) [21] & Seven-Day Physical Activity Recall Interview & kcal/day & $\downarrow$ & n.e. & $\uparrow$ & no \\
\hline \multirow[t]{3}{*}{ Donnelly et al. (2013) [26] } & Self-report & PA min./week & $\uparrow$ & n.e. & $\uparrow$ & no \\
\hline & & Steps/week & $\downarrow$ & n.e. & $\uparrow$ & no \\
\hline & Accelerometer & Counts/day & $\downarrow$ & n.e. & $\downarrow$ & no \\
\hline Huber et al. (2015) [24] & IPAQ & total METs/week & $\uparrow$ & n.e. & $\uparrow$ & no \\
\hline Hunter et al. (2008) [25] & IPAQ & total METs/week & - & n.e. & $\uparrow$ & no \\
\hline Kim et al. (2015) [31] & IPAQ-SF & total METs/week & $\uparrow^{*}$ & n.e. & $\uparrow$ & no \\
\hline Markham Risica et al. (2013) [22] & $\begin{array}{l}\text { Godin Leisure-Time Exercise } \\
\text { questionnaire }\end{array}$ & Total Leisure Activity Score & $\uparrow$ & n.e. & $\downarrow$ & no \\
\hline McConnon et al. (2007) [32] & Beacke physical activity Questionnaire & Score & n.d. & n.e. & n.d. & no \\
\hline Morgan et al. (2013) [33] & Pedometer & steps/day & $\uparrow^{*}$ & $\uparrow^{*}$ & $\uparrow$ & yes*/yes* \\
\hline Pellegrini et al. (2011) [34] & $\begin{array}{l}\text { Paffenbarger Physical Activity } \\
\text { Questionnaire, }\end{array}$ & $\mathrm{kcal} /$ week & $\uparrow^{*}$ & $\uparrow^{*}$ & $\uparrow^{*}$ & no/no \\
\hline Rogers et al. (2016) [35] & $\begin{array}{l}\text { Paffenbarger Physical Activity } \\
\text { Questionnair }\end{array}$ & $\mathrm{kcal} /$ week & $\uparrow$ & $\uparrow$ & $\uparrow$ & no/no \\
\hline \multirow[t]{2}{*}{ Routsalainen et al. (2015) [36] } & Physical Activity Questionnaire (WHO) & $\begin{array}{l}\text { days out of past } 7 \text { at least } \\
60 \text { min. of MVPA }\end{array}$ & $\uparrow$ & $\uparrow$ & $\uparrow$ & no/no \\
\hline & Accelerometer & MVPA min/day & $\uparrow$ & - & $\uparrow$ & no/no \\
\hline Ströbl et al. (2013) [37] & $\begin{array}{l}\text { Freiburg Questionnaire for Physical } \\
\text { Activity }\end{array}$ & $\begin{array}{l}\mathrm{h} / \text { week } \\
\mathrm{kcal} / \text { week }\end{array}$ & $\begin{array}{l}\uparrow^{*} \\
\uparrow^{*}\end{array}$ & $\begin{array}{l}\text { n.e. } \\
\text { n.e. }\end{array}$ & $\begin{array}{l}\uparrow^{*} \\
\uparrow\end{array}$ & $\begin{array}{l}\text { yes } \\
\text { yes }\end{array}$ \\
\hline Van Wier et al. (2009) [38] & SQUASH & Total PA (IQR) METmin./week & $\uparrow$ & $\uparrow$ & $\downarrow$ & yes/no \\
\hline Winett et al. (2007) [39] & Pedometer & steps/day & $\uparrow$ & $\uparrow$ & $\downarrow$ & no/yes \\
\hline
\end{tabular}

IG Intervention Group, CG Control Group, PA Physical Activity, $\uparrow$ improvement, $\downarrow$ deterioration, - no change, ${ }^{*}$ significant, n.e. not existing, n.d. no details

deemed their results to be significant, however did not provide any numerical values to support their claim. Further limits are missing data about effect size, since just two trials indicate their effect size at all. This strongly limits the interpretation of practical relevance.

In this presentation of results (Table 3) the last measuring points (follow-up data, if available) were continuously used for analysis. This leads to an extension of the study period by three to 18 months after baseline, depending on the study, and limits comparability. Just a few studies report significant time effects and time*group effect directly after intervention. Moreover, these few significances mostly disappear after follow-up. One explanation is the dwindling effect of the intervention.

Another limitation concerns validity as different measuring instruments were used to measure the physical activity level, e.g. different types and generations of accelerometer- or pedometer-based instruments by different providers. Also the self-reporting measuring instruments differ in content, quality and context (e.g. profession, leisure time, sports club etc.).

The clinical recommendations given in the following discussion are also limited due to lack of information about the therapy content. Nearly no information was provided or at least very short and limited explanations were given making it difficult to compare therapeutic approaches and, thus, limit the interpretation.

\section{Discussion}

Overall, this systematic literature shows a positive effect of media usage on physical activity levels in obesity treatment, taking into account the above-mentioned limitations. Physical activity in the intervention groups, measured by either duration, intensity, frequency or volume, increased in eleven trials and decreased in the other three trails. Comparable results can be found for the control groups (see Table 3). Accordingly, therapeutic approaches using digital media in obesity treatment did not show superior benefit over traditional therapeutic methods like face-to-face meetings of patient and therapist or the provision of printed (information) material.

The present analysis identified different study concepts. In most studies (8), the control groups received the same information as the intervention group only in written (print material) or verbal (face-to-face) form. Six studies did not support their control group at all during the intervention period. In three of those six studies the control group had the opportunity to participate in the full intervention after the end of the study (waiting list). One of 
those six studies applied a mixed design [22], i.e. the control group received little support during the intervention period and was added to the waiting list after the study. Interestingly, the latter study [22] shows a decrease in physical activity in the control group and an increase in physical activity in the intervention group. This study is also the only one which used various digital media in both, treatment and aftercare. There was no time* group effect. The increasing physical activity in the intervention group in contrast to the decreasing physical activity in the control group indicates a working concept for obesity treatment. In the other two studies [38, 39] with the same results, the time"group effect is only partially present and not significant. In total, four studies were found in which physical activity level increased in the intervention group compared to the control group. Only one study [33] shows a significant time:"group effect.

All studies reporting the desired effect of increased physical activity have one thing in common: All use a combination of digital media support and face-to-face consultations. This fact indicates that this mixed design is advisable in obesity treatment.

Within its limitations, practical recommendations for obesity treatment can be derived from the results of this systematic review. First, it is advisable to continue to integrate therapeutic personnel in obesity treatment and not to exclusively use digital media.

For example, in outpatient settings that commonly include less time for personal therapeutic support, the media-assisted approach is useful to increase physical activity in obesity patients. Here a simultaneous use of various digital media seems to be effective to address important aspects of behavior, e.g. nutrition and physical activity. However, it is still unclear if the used media need to be consumed on specific devices or rather in a certain combination of devices. For this purpose, more research is required [50]. As an example for a successful combination of digital media serves the study of Morgen et al. [33] - the only one with a significant time"group effect. It employed a combination of various online services with information about dietary and physical activity behavior, a DVD with practical exercises and a personal online diary that was used to provide personalized feedback by email [33].

In rural areas access to and accessibility of adequate therapy centers is mostly challenging and partly difficult to implement. In this case, media-assisted treatments and - particularly - aftercare has the potential to increase physical activity levels and, thus, contribute to the success of obesity therapy [26].

Furthermore, digital intervention concepts were well received by patients and seen as very helpful and supportive (see also [31, 37, 51]). This could be attributed, among other reasons, to the time saving aspect because of reduced travelling distances. In addition, digital therapy concepts can help to reduce barriers to allow and increase therapy participation, especially in rural areas [26].

Another important aspect of weight loss is selfmonitoring and this, in turn, can be supported simply by using digital devices for motivation [32]. However, personal care in obesity treatment is essential to achieve the intended effect.

From an economic perspective, digital media could offer a low-cost alternative in the long-term. Even if overall costs briefly increase due to development of adequate software and procurement of digital devices, they will decrease in time for the healthcare systems and the patiens as costs for human resources and travel expenses decline $[26,35,52]$.

\section{Conclusion}

In view of the increasing digitalization of our lifes, it seems only natural that media-assisted obesity treatment will increasingly become an integral part of obesity research and therapy [34]. The evidence in this issue is still unclear. This review of 14 randomized controlled trials (RCT) showed the greatest potential for a therapeutical approach using digital media for supporting obesity treatment in combination with a traditional face-to-face treatment. This result confirms already existing research in this field [53].

Nevertheless, major randomized controlled trials are necessary to identify effective methods for helping obese patients in the long term [36]. Existing studies provide initial indications on how to achieve intervention objectives and increase physical activity by using digital media. Through this, it is possible to implement efficient and resource-conserving concepts of intervention for both, the healthcare system and patients in the future. In order to build on existing success, adequate evaluation and further development of media-assisted obesity treatment and aftercare is required.

\section{Abbreviations}

BMI: Body Mass Index; MET: Metabolic Equivalent of Task; MVPA: Moderate to vigorous physical activity; PA: Physical Activity; PICO: Population, Intervention, Comparison, Outcome; PRISMA: Preferred Reporting Items of Systematic Reviews and Meta-Analysis; RCT: Randomized Controlled Trials

\section{Acknowledgements}

Not applicable.

\section{Authors' contributions}

AZ: Conception of research protocol, literature review, data extraction, data analysis, interpretation and drafting the manuscript. PW and HW: defining research question and idea of the design of the analysis plan, drafting and reviewing the manuscript, supervising the direction of the study, quality assessment. All authors read and approved the manuscript.

\section{Funding}

We have not obtained any fund for this study.

Availability of data and materials

Data will be available upon request of the corresponding author. 


\section{Ethics approval and consent to participate}

Not applicable.

\section{Consent for publication}

Not applicable.

\section{Competing interests}

The authors declare that they have no competing interests.

Received: 5 June 2019 Accepted: 12 February 2020

Published online: 21 February 2020

\section{References}

1. World Health Organization. Obesity and overweight-Fact sheet; 2017. Available from: URL: http://www.who.int/mediacentre/factsheets/fs311/en/.

2. Guh DP, Zhang W, Bansback N, Amarsi Z, Birmingham CL, Anis AH. The incidence of co-morbidities related to obesity and overweight: a systematic review and meta-analysis. BMC Public Health. 2009;9(1):1197. https://doi.org/ 10.1186/1471-2458-9-88.

3. John J, Wolfenstetter SB, Wenig CM. An economic perspective on childhood obesity: recent findings on cost of illness and cost effectiveness of interventions. Nutrition. 2012;28(9):829-39. https://doi.org/10.1016/j.nut. 2011.11.016

4. Sedentary Behaviour Research Networ. Letter to the editor: standardized use of the terms "sedentary" and "sedentary behaviours". Appl Physiol Nutr Metab. 2012;37(3):540-2. https://doi.org/10.1139/h2012-024.

5. König D. Bewegung, Übergewicht und Adipositas. In: Banzer W, editor Körperliche Aktivität und Gesundheit. Berlin: Springer; 2017. p. 189-98.

6. Anderson J. Interventions on diet and physical activity: what works : summary report. Geneva: World Health Organization; 2009.

7. Branca F, editor. Die Herausforderung Adipositas und Strategien zu ihrer Bekämpfung in der Europäischen Region der WHO: Zusammenfassung. Kopenhagen: WHO Regionalbüro für Europa; 2007.

8. Tsigos C, Hainer V, Basdevant A, Finer N, Fried M, Mathus-Vliegen E, et al. Management of obesity in adults: European clinical practice guidelines. Obes Facts. 2008;1(2):106-16. https://doi.org/10.1159/000126822.

9. McAuley A. Digital health interventions: widening access or widening inequalities? Public Health. 2014;128(12):1118-20. https://doi.org/10.1016/j. puhe.2014.10.008

10. Dorn SD. Digital health: hope, hype, and Amara's law. Gastroenterology. 2015;149(3):516-20. https://doi.org/10.1053/j.gastro.2015.07.024.

11. Williams DM, Raynor HA, Ciccolo JT. A review of TV viewing and its association with health outcomes in adults. Am J Lifestyle Med. 2008;2(3): 250-9. https://doi.org/10.1177/1559827608314104.

12. Lynch BM. Sedentary behavior and cancer: a systematic review of the literature and proposed biological mechanisms. Cancer Epidemiol Biomark Prev. 2010;19(11):2691-709. https://doi.org/10.1158/1055-9965.EPI-10-0815.

13. Lehmkuhl G, Frölich J. Neue Medien und ihre Folgen für Kinder und Jugendliche. Zeitschrift für Kinder- und Jugendpsychiatrie und Psychotherapie. 2013:41(2):83-6. https://doi.org/10.1024/1422-4917/a000215.

14. Grøntved A. Television viewing and risk of type 2 diabetes, cardiovascular disease, and all-cause mortality. JAMA. 2011;305(23):2448. https://doi.org/10. 1001/jama.2011.812.

15. Ford ES, Caspersen CJ. Sedentary behaviour and cardiovascular disease: a review of prospective studies. Int J Epidemiol. 2012:41(5):1338-53. https:// doi.org/10.1093/ije/dys078.

16. Biswas A, Oh Pl, Faulkner GE, Bajaj RR, Silver MA, Mitchell MS, et al. Sedentary time and its association with risk for disease incidence, mortality, and hospitalization in adults: a systematic review and meta-analysis. Ann Intern Med. 2015;162(2):123-32. https://doi.org/10.7326/M14-1651.

17. Edwardson CL, Gorely T, Davies MJ, Gray LJ, Khunti K, Wilmot EG, et al. Association of sedentary behaviour with metabolic syndrome: a metaanalysis. PLoS One. 2012;7(4):e34916. https://doi.org/10.1371/journal.pone. 0034916.

18. Becker S, Miron-Shatz T, Schumacher N, Krocza J, Diamantidis C, Albrecht UV. mHealth 2.0: experiences, possibilities, and perspectives. JMIR Mhealth Uhealth. 2014;2(2):e24. https://doi.org/10.2196/mhealth.3328.

19. Free C, Phillips G, Watson L, Galli L, Felix L, Edwards P, et al. The effectiveness of mobile-health technologies to improve health care service delivery processes: a systematic review and meta-analysis. PLoS Med. 2013; 10(1):e1001363. https://doi.org/10.1371/journal.pmed.1001363.
20. Raaijmakers LCH, Pouwels S, Berghuis KA, Nienhuijs SW. Technology-based interventions in the treatment of overweight and obesity: a systematic review. Appetite. 2015;95:138-51. https://doi.org/10.1016/j.appet.2015.07.008.

21. Cussler EC, Teixeira PJ, Going SB, Houtkooper LB, Metcalfe LL, Blew RM, et al. Maintenance of weight loss in overweight middle-aged women through the internet. Obesity (Silver Spring). 2008;16(5):1052-60. https://doi.org/10. 1038/oby.2008.19.

22. Risica P, Gans KM, Kumanyika S, Kirtania U, Lasater TM. SisterTalk: final results of a culturally tailored cable television delivered weight control program for black women. Int J Behav Nutr Phys Act. 2013;10(1):141. https://doi.org/10. 1186/1479-5868-10-141.

23. Abraham AA, Chow W-C, So H-K, Yip BH-K, Li AM, Kumta SM, et al. Lifestyle intervention using an internet-based curriculum with cell phone reminders for obese Chinese teens: a randomized controlled study. PLoS One. 2015; 10(5):e0125673. https://doi.org/10.1371/journal.pone.0125673.

24. Huber JM, Shapiro JS, Wieland ML, Croghan IT, Vickers DKS, Schroeder DR, et al. Telecoaching plus a portion control plate for weight care management: a randomized trial. Trials. 2015;16:323. https://doi.org/10.1186/ s13063-015-0880-1.

25. Hunter CM, Peterson AL, Alvarez LM, Poston WC, Brundige AR, Haddock CK, et al. Weight management using the internet a randomized controlled trial. Am J Prev Med. 2008;34(2):119-26. https://doi.org/10.1016/j.amepre.2007.09.026.

26. Donnelly JE, Goetz J, Gibson C, Sullivan DK, Lee R, Smith BK, et al. Equivalent weight loss for weight management programs delivered by phone and clinic. Obesity (Silver Spring). 2013;21(10):1951-9. https://doi.org/10.1002/ oby.20334.

27. Universitätsklinikum Freiburg / Deutsches Cochrane Zentrum. Manual Systematische Literaturrecherche für die Erstellung von Leitlinien; 2013.

28. Moher D, Liberati A, Tetzlaff J, Altman DG. Preferred reporting items for systematic reviews and meta-analyses: the PRISMA statement. PLoS Med. 2009;6(7):e1000097. https://doi.org/10.1371/ journal.pmed.1000097.

29. World Health Organization (WHO). Global recommendations on physical activity for health. Switzerland: WHO; 2010.

30. Cochrane Deutschland, Arbeitsgemeinschaft der Wissenschaftlichen Medizinischen Fachgesellschaften - Institut für Medizinisches Wissensmanagement. Bewertung des Biasrisikos (Risiko systematischer Fehler) in klinischen Studien: ein Manual für die Leitlinienerstellung 2016.

31. Kim J-Y, Oh S, Steinhubl S, Kim S, Bae WK, Han JS, et al. Effectiveness of 6 months of tailored text message reminders for obese male participants in a worksite weight loss program: randomized controlled trial. JMIR Mhealth Uhealth. 2015;3(1):e14. https://doi.org/10.2196/mhealth.3949.

32. McConnon A, Kirk SF, Cockroft JE, Harvey EL, Greenwood DC, Thomas JD, et al. The internet for weight control in an obese sample: results of a randomised controlled trial. BMC Health Serv Res. 2007;7:206. https://doi. org/10.1186/1472-6963-7-206.

33. Morgan PJ, Callister R, Collins CE, Plotnikoff RC, Young MD, Berry N, et al. The SHED-IT community trial: a randomized controlled trial of internet- and paper-based weight loss programs tailored for overweight and obese men. Ann Behav Med. 2013;45(2):139-52. https://doi.org/10.1007/s12160-0129424-z.

34. Pellegrini CA, Verba SD, Otto AD, Helsel DL, Davis KK, Jakicic JM. The comparison of a technology-based system and an in-person behavioral weight loss intervention. Obesity (Silver Spring). 2012;20(2):356-63. https:// doi.org/10.1038/oby.2011.13

35. Rogers RJ, Lang W, Barone Gibbs B, Davis KK, Burke LE, Kovacs SJ, et al. Applying a technology-based system for weight loss in adults with obesity. Obes Sci Pract. 2016;2(1):3-12. https://doi.org/10.1002/osp4.18.

36. Ruotsalainen $H$, Kyngäs $H$, Tammelin $T$, Heikkinen $H$, Kääriäinen $M$. Effectiveness of Facebook-delivered lifestyle Counselling and physical activity self-monitoring on physical activity and body mass index in overweight and obese adolescents: a randomized controlled trial. Nurs Res Pract. 2015;2015:159-205. https://doi.org/10.1155/2015/159205.

37. Ströbl V, Knisel W, Landgraf U, Faller H. A combined planning and telephone aftercare intervention for obese patients: effects on physical activity and body weight after one year. J Rehabil Med. 2013;45(2):198-205. https://doi.org/10.2340/16501977-1095.

38. van Wier MF, Ariëns GAM, Dekkers JC, Hendriksen IJM, Smid T, van Mechelen W. Phone and e-mail counselling are effective for weight management in an overweight working population: a randomized controlled trial. BMC Public Health. 2009;9:6. https://doi.org/10.1186/14712458-9-6. 
39. Winett RA, Anderson ES, Wojcik JR, Winett SG, Bowden T. Guide to health: nutrition and physical activity outcomes of a group-randomized trial of an internet-based intervention in churches. Ann Behav Med. 2007;33(3):251-61. https://doi.org/10.1080/08836610701358045.

40. Craig CL, Marshall AL, Sjöström M, Bauman AE, Booth ML, Ainsworth BE, et al. International physical activity questionnaire: 12-country reliability and validity. Med Sci Sports Exerc. 2003;35(8):1381-95. https://doi.org/10.1249/01. MSS.0000078924.61453.FB.

41. Chun MY. Validity and reliability of Korean version of international physical activity questionnaire short form in the elderly. Korean J Fam Med. 2012; 33(3):144. https://doi.org/10.4082/kffm.2012.33.3.144.

42. Sallis JF, Haskell WL, Wood PD, Fortmann SP, Rogers T, Blair SN, et al. Physical activity assessment methodology in the Five-City project. Am J Epidemiol. 1985;121(1):91-106.

43. Paffenbarger RS, Hyde RT, Wing AL, Hsieh CC. Physical activity, all-cause mortality, and longevity of college alumni. N Engl J Med. 1986;314(10):60513. https://doi.org/10.1056/NEJM198603063141003.

44. Currie C, Zanotti C, Morgan A, Currie D, de Looze M, Roberts C, Samdal O, Smith ORF, Barnekow V. Social Determinants of Health and Well-being among Young People: Health Behaviour in School-aged Children (HSBC) Study: International Report from the 2009/2010 Survey. Geneva: World Health Organization; 2012. Available from: URL: http://gbv.eblib.com/patron/ FullRecord.aspx?p=1582985

45. Frey I, Berg A, Grathwohl D, Keul J. Freiburger Fragebogen zur körperlichen Aktivität-Entwicklung, Prüfung und Anwendung. Soz Präventivmed. 1999; 44(2):55-64. https://doi.org/10.1007/BF01667127.

46. Wendel-Vos G. Reproducibility and relative validity of the short questionnaire to assess health-enhancing physical activity. J Clin Epidemiol. 2003;56(12):1163-9. https://doi.org/10.1016/S0895-4356(03)00220-8.

47. Baecke JA, Burema J, Frijters JER. A short questionnaire for the measurement of habitual physical activity in epidemiological studies. Am J Clin Nutr. 1982;36(5):936-42. https://doi.org/10.1093/ajcn/36.5.936.

48. Godin G, Shephard RJ. A simple method to assess exercise behavior in the community. Can J Appl Sport Sci. 1985;10(3):141-6

49. Lenhard W, Lenhard A. Computation of Effect Sizes; 2014

50. Matsumoto Y, Yoshiuchi S, Miyauchi T, Hayashi H, Habu D, Kimura Y. Utility of a web-based weight loss program with auto-extraction of behavioural objectives and recording of daily weight and steps in pre-obese outpatients. Asia Pac J Clin Nutr. 2014;23(3):473-80. https://doi.org/10.6133/ apjcn.2014.23.3.17.

51. Chen J-L, Wilkosz ME. Efficacy of technology-based interventions for obesity prevention in adolescents: a systematic review. AHMT. 2014;159. https://doi. org/10.2147/AHMT.S39969.

52. Castelnuovo G, Manzoni GM, Pietrabissa G, Corti S, Giusti EM, Molinari E, et al. Obesity and outpatient rehabilitation using mobile technologies: the potential mHealth approach. Front Psychol. 2014;5:559. https://doi.org/10. 3389/fpsyg.2014.00559

53. Kodama S, Saito K, Tanaka S, Horikawa C, Fujiwara K, Hirasawa R, et al. Effect of web-based lifestyle modification on weight control: a meta-analysis. Int J Obes. 2012;36(5):675-85. https://doi.org/10.1038/ijo.2011.121.

\section{Publisher's Note}

Springer Nature remains neutral with regard to jurisdictional claims in published maps and institutional affiliations.

Ready to submit your research? Choose BMC and benefit from:
- fast, convenient online submission
- thorough peer review by experienced researchers in your field
- rapid publication on acceptance
- support for research data, including large and complex data types
- gold Open Access which fosters wider collaboration and increased citations
- maximum visibility for your research: over 100M website views per year
At BMC, research is always in progress.
Learn more biomedcentral.com/submissions

